\title{
Using resonant synchrotron X-ray diffraction technique to improve the identification of crystalline markers in atmospheric particulate matter
}

\author{
Galvão, E. S. ${ }^{1 *}$; Orlando, M. T. D. ${ }^{1}$ \\ 1 Departamento de Física, Universidade Federal do Espírito Santo, Vitória, ES, Brasil.
}

* e-mail: elsongalvao@gmail.com

\begin{abstract}
The knowledge of the particulate matter (PM) mineralogical composition is fundamental to understand the role of these particles in the atmosphere, that also can affect the human life. However, the characterization of the crystalline phases in the PM is a challenge concerning analytical issues, such as few sample mass and phases with low content. In this work, we present an alternative and powerful method based on the resonant synchrotron X-ray diffraction (RSr-XRD) for the analysis of crystalline phases in the PM, aiming the better identification of the mineral content. The results show that RSr-XRD method provided improved diffraction spectra with high resolution depending on the energy chosen. Energies far from the absorption edge of the major elements in the PM mineral phases provided more intense peaks and better signal-tonoise ratio, revealing important peaks not shown when the energy is closer to the absorption edge of the elements.
\end{abstract}

\begin{abstract}
Resumo
O conhecimento da composição mineralógica do material particulado (MP) é fundamental para entender o papel dessas partículas na atmosfera, que também podem afetar a vida humana. No entanto, a caracterização de fases cristalinas do MP é um desafio no que diz respeito a questões analíticas, como pouca massa de amostra e fases com baixo teor. Neste trabalho, apresentamos um método alternativo e poderoso baseado na difração ressonante de raios-X por luz síncrotron (RSr-XRD) para a análise de fases cristalinas no MP visando melhor identificação do conteúdo mineral. Os resultados mostram que o método RSr-XRD forneceu espectros de difração aprimorados com alta resolução dependendo da energia escolhida. Energias distantes da borda de absorção dos principais elementos nas fases minerais do MP proporcionaram picos mais intensos e melhores relações sinal-ruído, revelando picos importantes não mostrados quando a energia está mais próxima da borda de absorção dos elementos.
\end{abstract}

Keywords: resonant synchrotron X-ray diffraction (RSr-XRD); particulate matter; crystalline markers.

\section{Introduction}

The mineralogical characterization of the atmospheric particulate matter (PM) is fundamental to understand the role of these particles in the atmosphere and their effects on human health. A proper knowledge of the crystalline phases in the PM can render clues about the dominant sources contributing for these phases in the PM composition.

Though, the PM mineralogical characterization is a hard task because of the small amount of mass commonly sampled during environmental studies over a 24-hour period. A common condition caused by relatively low PM levels in the atmosphere (in the order of only a few micrograms per cubic meters). A critical value of PM mass for a reasonable identification of the crystalline phases by conventional XRD instruments is about 20 $\mu \mathrm{g} \cdot \mathrm{m}^{-2}$ of filter medium area [1]. Besides the critical PM mass, peak broad and overlapped peaks are other issues affecting the mineralogical characterization, especially of the fine fraction of the PM, those less than $10 \mu \mathrm{m}$ of diameter. In mixtures of over two phases, the analysis by conventional XRD may find difficulty in 
identify individual constituents because of the insufficient differences in the intensities of the elements [2]. It is noteworthy that environmental samples may present dozens of phases in their composition.

The high flux and resolution of the synchrotron sources is an excellent alternative for a good characterization of the PM mineralogical composition. The synchrotron Xray sources dates back to the 1970 s decade, and has experienced a rapid development since then, including the use of brilliance, tunable wavelength and polarization properties with application in the fields of protein phases and surface magnetism [3], besides environmental analysis.

\section{Methodology}

PM samples collected in the atmosphere of Vitória city, state of Espírito Santo, Brazil, were analyzed by Resonant X-ray Diffraction (RSr-XRD) method at the Laboratório Nacional de Luz Synchrotron (LNLS) in Campinas, Brazil. LNLS has a second-generation synchrotron source operating with the energy of 1.37 $\mathrm{GeV}$, that includes a $120 \mathrm{MeV}$ linear accelerator and a Booster of $500 \mathrm{MeV}$ operating with a current beam of $250 \mathrm{~mA}$ in decay-mode. RSr-XRD analysis was performed at XRD1 Beam Line, a dedicated diffraction line equipped with a 3-circle powder diffractometer (Newport®, USA) and an MYTHEN 24K detector (Dectris $\AA^{\circ}$, USA).

The XRD1 beam line energy was set in two distinct energies, the first one at $7.000 \mathrm{keV}(1.77108 \AA)$, energy close to the X-ray absorption edge of Fe $(7.112 \mathrm{keV}$, $1.7433 \AA)$, and a second one at $6.500 \mathrm{keV}(1.90741 \AA)$, an energy far from the X-ray absorption edge of $\mathrm{Fe}$, aiming to improve the scattering, intensity and resolution of the (Fe,Ba,Ti)-rich peaks [4].

\section{Results and Discussion}

The results show a comparison between the RSr-XRD analysis of a PM sample considering different energies away from the X-ray absorption edges of iron (Fe), barium $(\mathrm{Ba})$ and titanium $(\mathrm{Ti})$. The $\mathrm{X}$-ray absorption edges of these elements are: (i) Fe $\mathrm{K}=7.1120 \mathrm{keV}(\lambda=$ $0.17433 \mathrm{~nm})$; (ii) Ba L-I = $5.9888 \mathrm{keV}(\lambda=0.20703 \mathrm{~nm})$; and (ii) $\mathrm{TiK}=4.9664 \mathrm{keV}(\lambda=0.24965 \mathrm{~nm})$.

Figures 1 and 2 show the RSr-XRD spectra of the same PM sample, ranging from $30^{\circ}$ up to $80^{\circ}(2 \theta)$ measured at $7.0 \mathrm{keV}$ (Fig. 1), and from $30^{\circ}$ to $90^{\circ}(2 \theta)$ measured at $6.5 \mathrm{keV}$ (Fig. 2). As shown in Figure 1, the diffraction peaks corresponding to hematite $\left(\alpha-\mathrm{Fe}_{2} \mathrm{O}_{3}\right)$ measured at $7.0 \mathrm{keV}$ (closer to the energy of $\mathrm{Fe} \mathrm{K}$ edge) presents peaks less intense and poorly defined (main peaks at $38.4^{\circ}, 41.2^{\circ}, 57.4^{\circ}, 63.1^{\circ}, 73.1^{\circ}$ and $75.1^{\circ}-$ measured at
$7 \mathrm{keV}$; PDF card \#33-664) than those measured at $6.500 \mathrm{keV}$ (Fig. 2). In Figure 2, the diffraction peaks corresponding to hematite measured at $6.5 \mathrm{keV}$ (farther from the Fe $\mathrm{K}$ edge) are more intense and well defined.

The results in Figures 1 and 2 show that the adjustment of energies in the synchrotron source far away from the absorption edge of $\mathrm{Fe}$ resulted in improved diffraction peaks with better intensity and resolution. Therefore, it is possible to state that the better resolution and signalto-noise ratio provided by the $\mathrm{RSr}-\mathrm{XRD}$ technique allows a good characterization of the mineralogical phases in the PM, even for samples with a few mass, low phase content, or large number of phases in the PM.

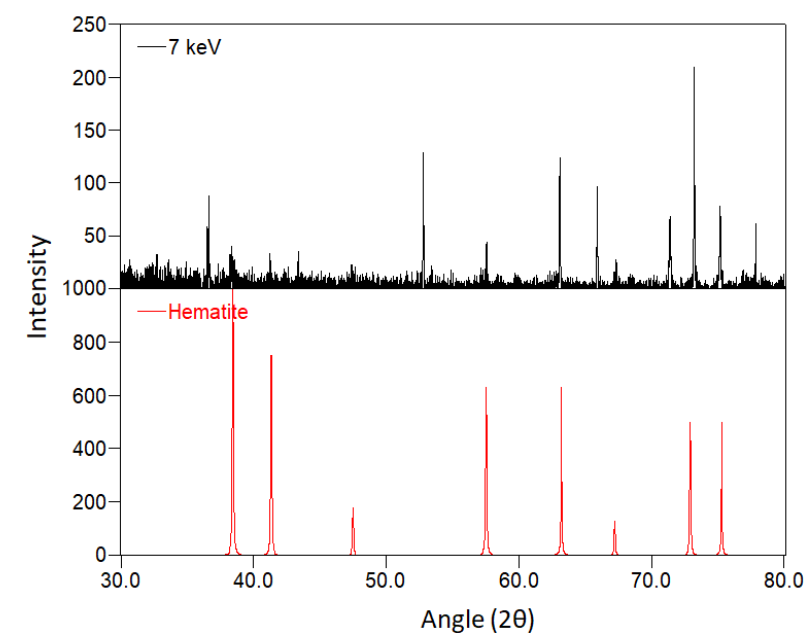

Figure 1. RSr-XRD spectra of the PM sample measures at $7 \mathrm{keV}$, and the hematite diffraction pattern (PDF card \#33-664).

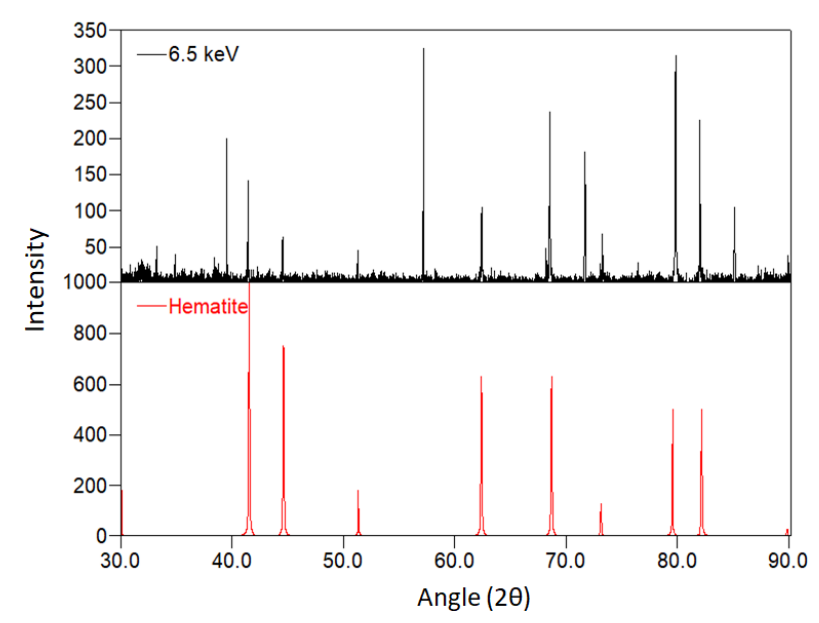

Figure 2. RSr-XRD spectra of the PM sample measures at $6.5 \mathrm{keV}$, and the hematite diffraction pattern (PDF card \#33-664).

The X-ray resonant scattering allowed a more selective analysis of the crystalline phases in the PM samples than conventional XRD method. The set of the energy of $6.5 \mathrm{keV}$, a value $0.6120 \mathrm{keV}$ far from the Fe $\mathrm{K}$ edge $(7.1120 \mathrm{keV})$ provided diffraction spectra with peaks more intense and with better resolution because of the 
improvements in the atomic scattering factor $f(Q, E)$, which is dependent of the real and imaginary components of the anomalous dispersion terms [2], respectively, $f^{\prime}(E)$ and $f^{\prime \prime}(E)$, as shown in Equations 1 and 2. $f^{\prime}(E)$ is associated with the elastic scattering (without absorption), while $f^{\prime \prime}(E)$ is associated with the intensity losses because of the effects of X-ray absorption.

$$
\begin{gathered}
I(E) \propto\left[F_{h k l}\right] ; \text { for: } F_{h k l}=\sum x_{i} \cdot \boldsymbol{f}(\boldsymbol{Q}, \boldsymbol{E}) \cdot e^{2 \pi i(h x+k y+l z)} \\
f(Q, E)=f_{0}(Q)+f^{\prime}(E)+i f^{\prime \prime}(E)
\end{gathered}
$$

Therefore, the use of the energy of $6.5 \mathrm{keV}$ has maximized the scattering and reduced the absorption of X-rays, yielding improved results even for PM samples with a few mass or phases with low contents.

The strength of the RSr-XRD method is clearer in the results associated with Figures 3 and 4, concerning the phase barium titanate $\left(\mathrm{BaTiO}_{3}\right)$. Figures 3 and 4 show the RSr-XRD spectra of the same PM sample, ranging from $35^{\circ}$ up to $38^{\circ}(2 \theta)$ measured at $7 \mathrm{keV}$ (Fig. 3), and from $38^{\circ}$ to $41^{\circ}(2 \theta)$ measured at $6.5 \mathrm{keV}$ (Fig. 4).

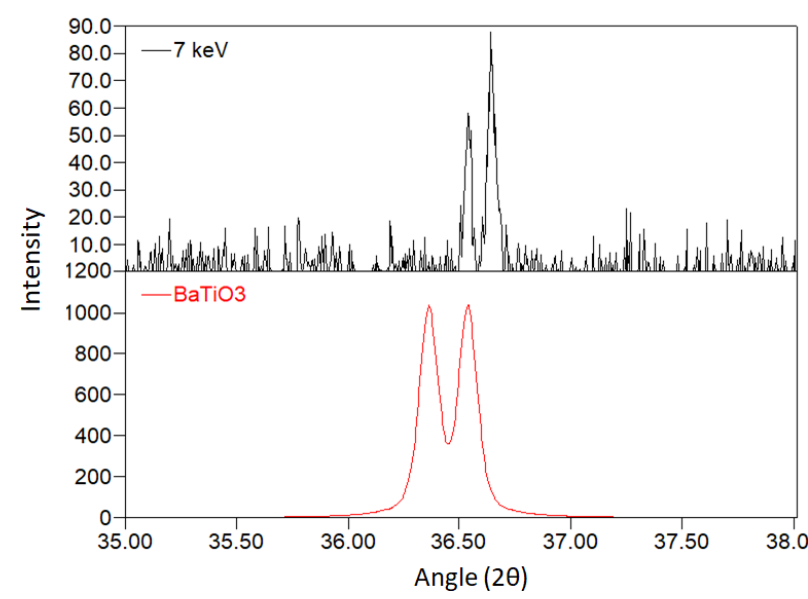

Figure 3. RSr-XRD spectra of the PM sample measures at $7 \mathrm{keV}$, and the $\mathrm{BaTiO}_{3}$ diffraction pattern (PDF card \#5-626).

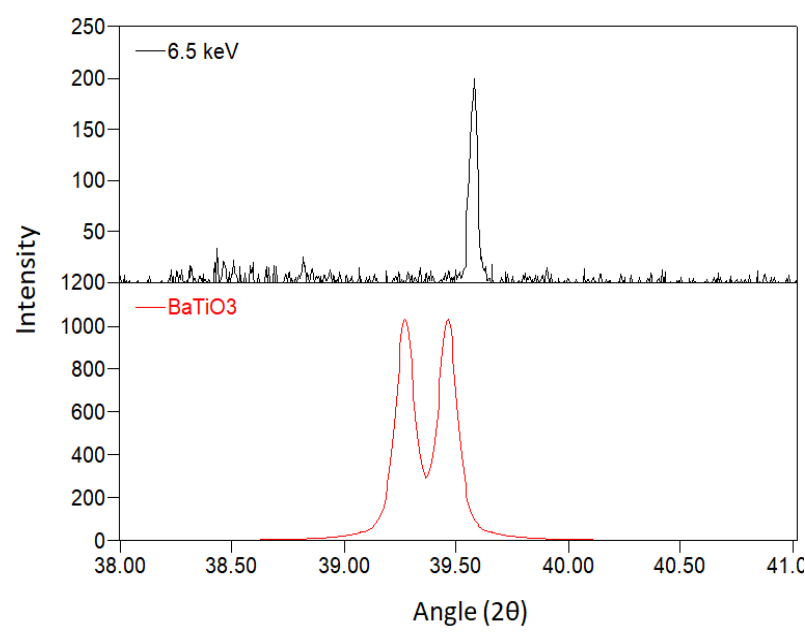

Figure 4. RSr-XRD spectra of the PM sample measures at $6.5 \mathrm{keV}$, and the $\mathrm{BaTiO}_{3}$ diffraction pattern (PDF card \#5-626).
As shown in Figure 3, the use of the energy of $7.0 \mathrm{keV}$, an energy $1.012 \mathrm{keV}$ and $2.034 \mathrm{keV}$ farther from the absorption edges of the $\mathrm{Ba}$ and $\mathrm{Ti}$, respectively, provided improved identification of the major peaks of the $\mathrm{BaTiO}_{3}$ at $36.5^{\circ}$ and $36.6^{\circ}(2 \theta$ at $7 \mathrm{keV})$. However, these two peaks were not identified using the energy of $6.5 \mathrm{keV}$, an energy closer to Ba L-I absorption edge, as shown in Figure 4 that depicts a single peak at $39.6^{\circ}$. The $\mathrm{BaTiO}_{3}$ peaks at $36.5^{\circ}$ and $36.6^{\circ}$ in Figure 3 were only identified by the application of the RSr-XRD technique with the use of an appropriated energy. The resonant scattering using the energy of $7.0 \mathrm{keV}$ provided improved resolution and separation of these two peaks that are separated for only $0.0012 \mathrm{~nm}$. $\mathrm{BaTiO}_{3}$ was reported in the literature as an important marker of vehicular brake emissions in the atmosphere, and its identification is crucial for the control of air pollution sources [5].

\section{Conclusion}

The RSr-XRD technique can provide a more selective analysis of the crystalline phases in the PM samples than conventional XRD method. Using specific energies far from the absorption edges of the major elements in the crystalline phases improve the resolution and intensities of the major peaks. This result in more reliable XRD spectra, and allow the identification and quantification of the PM mineralogical composition, even for samples with few mass or low crystalline phases contents.

\section{Acknowledgements}

The authors would like to acknowledge CNPq ARC303333/2019-7, CAPES and the Brazilian Synchrotron Light Source (LNLS, CNPEM - Campinas) for the technical support and use of its beamline XRD-1, Proposals 20170383 and 20170108.

\section{References}

[1] MACHEMER, S.D., 2004. Characterization of Airborne and Bulk Particulate from Iron and Steel Manufacturing Facilities. Environ. Sci. Technol. 38, 381-389. https://doi.org/10.1021/es020897v

[2] WASEDA, Y. Nature of Anomalous X-ray Scattering and Its Application to the Structural Analysis of Crystalline and Non-Crystalline Systems, in Anomalous X-ray scattering for Materials Characterization. Springer, Berlin, 2002, p. 21.

[3] MATERLIK, G., SPARKS, C.J., and FISHER, K., Resonant Anomalous X-Ray Scattering: Theory and Applications. Elsevier Science, Amsterdam, 


\section{$10^{\text {th }}$ Workshop of Applied Crystallography}

UFES, Vitória - ES, Brasil, December2020

1994.

[4] FERREIRA, F.F, BUENO, P.R., SETTI, G.O., GIMÉNEZ-ROMERO, D., GARCÍA-JAREÑO, J.J, VICENTE, F., 2008. 2008. Resonant x-ray diffraction as a tool to calculate mixed valence ratios: application to Prussian Blue materials. Appl. Phys. Lett. 92, 264103. https://doi.org/10.1063/1.2952457.
[5] GALVÃO, E.S., SANTOS, J.M., LIMA, A.T., REIS, N.C., STUETZ, R.M., ORLANDO, M.T.D., 2018. Resonant Synchrotron X-ray Diffraction determines markers for iron-rich atmospheric particulate matter in urban region. Chemosphere 212, 418-428. https://doi.org/https://doi.org/10.1016/j.chemosphe re.2018.08.111. 